\title{
SOCIALLY RESPONSIBLE INVESTING RETURNS: EVIDENCE FROM SOUTH AFRICA, 2004-2012
}

\author{
Munyaradzi Chawana* \\ University of Johannesburg \\ mchawana@gmail.com
}

Received: August 2013

Accepted: February 2014

\begin{abstract}
A number of researchers have sought to test the theoretical prediction of Modern Portfolio Theory that asserts that Socially Responsible Investing (SRI) under-performs conventional investing. In contrast to the majority of literature, which focuses on comparing SRI funds' performance to conventional funds, this study compares the performance of South Africa's JSE SRI Index to the performance of local conventional market indices in the period 2004-2012. Using Sharpe ratios, the results of the study indicate that in comparison to conventional indices, the JSE SRI Index generally exhibits an inferior risk-return trade-off in both bull and bear market conditions. Furthermore, spanning tests based on the single-factor Capital Asset Pricing Model provide evidence that the JSE SRI Index is only likely to earn similar risk-adjusted returns to the Synthetic Conventional Index (a self-constructed index tracking non-overlapping conventional stocks). However, if the assumption of a non-restricted investment universe for a non-socially conscious investor is considered, there is a risk-adjusted return penalty for investing in the JSE SRI Index.
\end{abstract}

Keywords

Socially Responsible Investing, Risk-adjusted returns, Modern Portfolio Theory, Capital Asset Pricing Model, JSE SRI Index, Spanning test

*Mr M Chawana is a master's graduate from the Department of Finance \& Investment Management, University of Johannesburg, South Africa. 


\section{INTRODUCTION}

Interest in Socially Responsible Investing (SRI) has recently come to the fore globally. According to the Global Sustainable Investment Alliance's 2012 Global Sustainable Investment Review Report, professionally managed assets in 2012 with an SRI orientation constituted $21.8 \%$ (translating to US\$13.6 trillion) of the overall funds under management in Europe, the United States of America (USA), Asia, Australia, Canada, Japan and Africa. Tied to the heightened concerns on Corporate Social Responsibility, the growth in SRI can largely be attributed to the popularity in disfavouring the motive of profit maximisation at society's cost. As a consequence, calls have arisen for firms to assimilate expectations and concerns of all shareholders directly and indirectly influenced by a firm's corporate activities (stakeholder theory) through the integration of environment, social and corporate governance (ESG) concerns. Thus, in terms of investment decision-making process, SRI involves the selection of stocks on the basis that the underlying firms incorporate ESG concerns in their business practices (Huimin, Kong \& Eduardo, 2010; Barnett \& Salomon, 2006).

Even though there are undoubtedly plausible reasons why investors would opt for SRI, e.g. changing firm behaviour through funds redistribution from disapproved to approved activities (Knoll, 2002); the business case for SRI is still debatable. For investors who go beyond philanthropic affinities, the question of financial return is consequently vital. Hence, as is often stated, the question of how SRI performs relative to conventional investments calls for an empirical review. From a theoretical basis, SRI critics highlight that (i) increases in monitoring costs, and (ii) a restricted investment universe which limits potential for diversification results in SRI investments under-performing conventional investments. However, supporters of SRI contend that any loss in deriving mean-variance efficient portfolios as a result of a constrained investment universe is compensated for by the desirable profile characteristics (e.g. ability to raise funds (Waddock \& Graves, 1997); ability to hire a quality workforce (Greening \& Turban, 2000)) of the screened assets' underlying companies. This view is anchored in the belief that screens eliminate firms with undesirable characteristics that the market or society will eventually penalise over time (stakeholder theory).

To date, empirical evidence on the existence of performance differences between SRI and nonSRI is mixed at best. On the one hand there are studies that report that SRI under-performs nonSRI (Galema, Plantinga \& Scholtens, 2008; Renneboog, Horst \& Zhang, 2008; Lee, Humphrey, Benson \& Ahn, 2010; Hong \& Kostovetsky, 2012; Bauer, Koedijk \& Otten, 2005) and on the other hand there are studies that highlight that SRI out-performs non-SRI (Kempf \& Osthoff, 2007; Derwall, Guenster, Bauer, \& Koedijk, 2005; Derwall \& Koedijk, 2009). Furthermore, certain studies report no significant performance differences (Schröder, 2007; DiBartolomeo \& Kurtz, 1999; Bauer, Derwall \& Otten, 2007; Statman, 2000, 2006; Sauer, 1997).

With a wide array of ambiguous results predominantly from developed countries, it is worthwhile to empirically analyse the performance of SRI in a different market and position the results within the currently inconclusive literature. Accordingly, this study compares the risk-return profile of South Africa's Socially Responsible Index (launched by the JSE Limited (previously named the Johannesburg Stock Exchange and the JSE Securities Exchange South Africa) henceforth referred to as the JSE SRI Index) to that of local conventional market indices (i.e. FTSE/JSE All Share Index, FTSE/JSE Top 40 Index, FTSE/JSE Mid Cap Index and FTSE/JSE Small Cap Index). In contrast to most conventional studies that focus on comparing SRI funds to non-SRI funds and/or market indices, this study is in line with Statman (2006) and Schröder (2007) and 
makes complete use of indices as opposed to fund portfolios. Since indices are passive portfolios, using them to compare SRI to non-SRI is usually lauded for eliminating the following: (i) the need to consider market timing, (ii) correctly evaluating transaction costs and (iii) filtering out fund manager skill (Schröder, 2007). In addition, the use of indices indirectly satisfies the salient aspect of only including stocks that are available to the public (free float), whereas studies that employ synthetic portfolios usually fail to account for free float adjustments. In essence, this research seeks to answer the following:

- Are there risk-adjusted return differences between the JSE SRI Index and conventional market indices (FTSE/JSE Top 40 Index, FTSE/JSE All Share Index, FTSE/JSE Mid Cap Index and FTSE/JSE Small Cap Index)?

- Do different market conditions (bear vs. bull) influence the financial performance the JSE SRI Index and conventional market indices (FTSE/JSE Top 40 Index, FTSE/JSE All Share Index, FTSE/JSE Mid Cap Index and FTSE/JSE Small Cap Index) differently?

The contribution of this study is threefold. First, this is one of only a few studies that focus on South Africa, an emerging market. The majority of studies of this nature have been done for the US and European countries, with relatively little research on emerging markets. Additionally, while SRI consciousness has grown steadily in South Africa; there is a paucity of research in the SRI domain. Of the limited research available, the majority of studies delve into (i) the profile of the South African responsible investing industry and opportunities and challenges in the SRI sector (e.g. Heese, 2005; Viviers, Bosch, Smit \& Buijs, 2009; Herringer, Firer \& Viviers, 2009) and (ii) the degree to which investors integrate ESG factors into their investment choices (e.g. Giamporcaro \& Pretorius 2012; Eccles, Nicholls \& De Jongh, 2008). Moreover, the question of financial performance of SRI in South Africa has been tackled only at the fund level (e.g. Viviers, Bosch, Smit \& Buijs, 2008). Second, the study period considered is extensive. Monthly data from the inception (May 2004) of the JSE SRI Index to August 2012 is employed. This period captures both bull and bear market conditions (determined in the same way as in Natarajan, 2011), allowing assessment of how different market conditions influence financial performance of the indices under consideration. Third, and possibly the most important, the JSE SRI Index is also compared to a synthetically constructed index that tracks non-overlapping conventional stocks between the JSE SRI Index and the FTSE/JSE All Share Index (market benchmark). The synthetically constructed index allows for the testing of the financial performance hypothesis of pure conventional stocks against pure SRI stocks. Some previous studies (Schröder, 2007) did not endeavour to disentangle the benchmark into $S R$ and non-SR stocks before conducting performance analysis.

The remainder of the paper is organised as follows: in the following section the JSE SRI Index background and selection criteria are presented. In the third section a discussion of previous literature is given. The fourth section introduces the methodology used. Results and discussion of the findings is given in section five. Conclusions are given in the last section.

\section{JSE SRI INDEX BACKGROUND \& SELECTION CRITERIA}

The Domini 400 Social Index (later renamed the FTSE/KLD 400 Social Index) was the first SRI Index to be launched in the USA and the world. Fourteen years later, in South Africa the JSE Limited launched the JSE SRI Index, and it became the first exchange and emerging market launched sustainability index (JSE Limited, 2011). According to the JSE Limited (2011), the index 
was established to act primarily as a: (i) a tool for tracking JSE listed companies with commendable sustainability business practices and (ii) a facilitating vehicle for responsible investment. Including in its universe companies from all sectors and with no sector down weightings, the JSE SRI Index can generally be classified as a positive screening index as it focuses on identifying companies with positive social impact rather than excluding companies from the index based on certain factors.

Influenced by the King II Report (and the subsequent King III) on Corporate Governance and the United Nations Principles for Responsible Investment, the criterion set to measure how companies integrate sustainable principles follows the triple bottom line (Environment, Society and Governance $(\varepsilon S G)$ ) framework. In line with burgeoning global climate concerns, the JSE Limited introduced an additional requirement in 2010 that focuses on climate change. FIGURE 1 illustrates the issues (ESG concerns and climate change) that companies must satisfy for inclusion in the JSE SRI Index.

\section{Environment}

- Addressing all key issues

- Working towards environmental sustainability

\section{Society}

- Training \& Development

- Employee Relations

- Health \& Safety

- Equal Opportunities

- Community Relations

- Stakeholder Engagement

- Black Economic Empowerment

- HIV / Aids

\section{Governance and related sustainability concerns}

\section{- Board Practice}

- Ethics

- Indirect Impacts

- Business Value \& Risk Management

- Broader Economic Issues

\section{Climate change}

- Managing and reporting on efforts aimed at reducing carbon emissions to deal with the anticipated effects of climate change

FIGURE 1: Areas of measurement

\section{Source: JSE Limited (2011)}


For each area of measurement illustrated in FIGURE 1, companies are assessed in terms of policy, management and performance and reporting. In terms of policy, companies are required to establish policies that identify environmental, economic and social challenges. In terms of management and performance, companies are evaluated on the extent to which management ensures that policies for environmental, economic and social challenges are implemented, and that the achievement of targets set in such policies is monitored and measured. The reporting requirement assesses the extent to which companies provide timely information and access to this information to stakeholders. A company qualifies to be a JSE SRI Index constituent if it satisfies the minimum core - must have and desirable indicators (aspirational) set out in TABLE 1 .

\section{TABLE 1 Minimum Selection Requirements}

\begin{tabular}{|c|c|c|c|c|}
\hline & & High Impact & Medium Impact & Low Impact \\
\hline & $\frac{\text { ò }}{\circ}$ & $\begin{array}{l}\text { Policy must be publicly } \\
\text { available, and: } \\
\text { - All five core } \\
\text { indicators plus at } \\
\text { least one desirable; } \\
\text { or } \\
\text { - Four core plus two } \\
\text { desirable indicators. }\end{array}$ & $\begin{array}{l}\text { Four indicators, at least } \\
\frac{\text { three of which must be }}{\text { core }}\end{array}$ & $\begin{array}{l}\text { Must have published a } \\
\text { policy statement } \\
\text { including at least one } \\
\text { core or desirable } \\
\text { indicator, } \underline{0 R} \text { meet either } \\
\text { the management or } \\
\text { reporting requirement. }\end{array}$ \\
\hline \multirow[t]{2}{*}{ 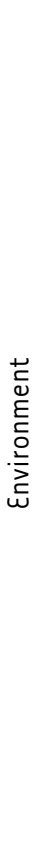 } & 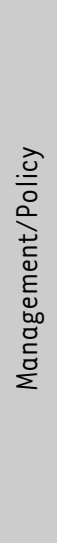 & $\begin{array}{l}\text { Depending on coverage } \\
\text { of EMS: } \\
\text { - Six indicators, and } \\
\text { quantified targets; or } \\
\text { - Five indicators, } \\
\text { including } \\
\text { documented } \\
\text { objectives and } \\
\text { targets ISO } \\
\text { certification or EMAS } \\
\text { registrations are } \\
\text { considered to meet } \\
\text { all indicators }\end{array}$ & $\begin{array}{l}\text { Depending on coverage } \\
\text { of EMS: } \\
\text { - Four indicators; or } \\
\text { - Six indicators, } \\
\text { including } \\
\text { documented } \\
\text { quantitative } \\
\text { objectives and } \\
\text { targets. } \\
\text { ISO certification or EMAS } \\
\text { registrations are } \\
\text { considered to meet all } \\
\text { indicators. }\end{array}$ & $\begin{array}{l}\text { Must have completed an } \\
\text { initial /baseline review } \\
\text { to identify significant } \\
\text { impacts, } \underline{0 R} \text { meet either } \\
\text { the policy or reporting } \\
\text { requirement }\end{array}$ \\
\hline & 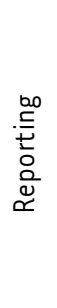 & $\begin{array}{l}\text { The report must cover } \\
\text { the whole group }{ }^{2} \text {, and } \\
\text { meet at least two } \\
\text { indicators (including } \\
\text { text of environmental } \\
\text { policy), plus one } \\
\text { desirable reporting } \\
\text { indicator. }\end{array}$ & $\begin{array}{l}\text { The report must cover } \\
\text { the whole group }{ }^{2} \text {, and } \\
\text { include text of } \\
\text { environmental policy } \\
\text { plus one other reporting } \\
\text { indicator. }\end{array}$ & $\begin{array}{l}\text { The report must cover } \\
\text { the whole group }{ }^{2} \text {, and } \\
\text { include text of } \\
\text { environmental policy } \underline{O R} \\
\text { meet either the policy or } \\
\text { management } \\
\text { requirement. }\end{array}$ \\
\hline
\end{tabular}

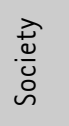

- A company must meet the majority ${ }^{3}$ of all indicators, of which one-third $(1 / 3)$ must be core

- In addition to the general requirement, companies operating in South Africa must meet 


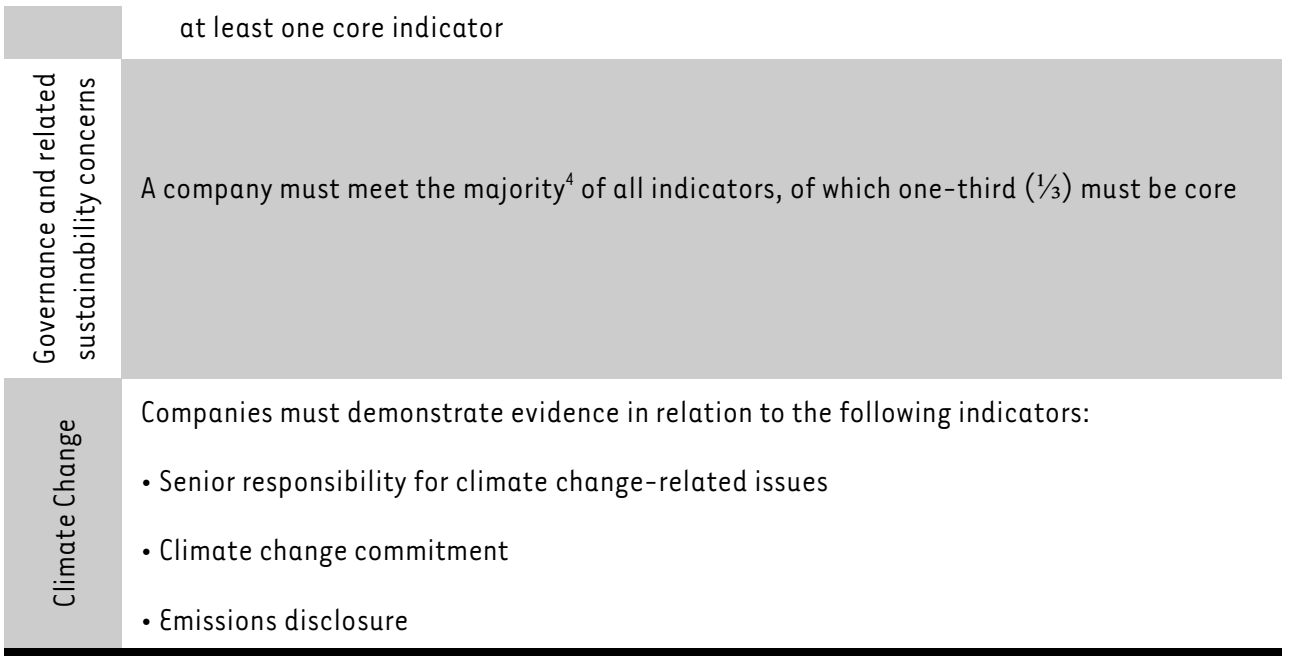

Source: JSE Limited (2011)

Notes: Requirements for the 2011 review; "Whole group" is defined as <95\% of operations; "Majority" in this context means half ( $50 \%$ ) of all indicators (core and desirable), plus one; "Majority" in this context means half $(50 \%)$ of all indicators (core and desirable), plus one

The eligible universe of companies for inclusion in the index is drawn from the FTSE/JSE All Share Index (top 160 companies by market capitalisation). The free float market capitalisation method is utilised to determine within-index stock weights. Since the JSE SRI Index is not static, it is reviewed annually and companies have to satisfy an evolving selection criterion. For each annual review, the Top 100 (Top 40 and Mid Cap) companies as well as the preceding SRI Index constituents are automatically assessed. For the FTSE/JSE Small Cap Index companies, assessment is voluntary. Any company that is expelled from the FTSE/JSE All Share Index during the Index's quarterly review or at any other time is automatically ineligible for inclusion in the JSE SRI Index. TABLE I shows the growth of the JSE SRI Index in terms of constituents: from 51 companies in 2004, the JSE SRI Index boasted of 74 companies as at the end of 2011.

TABLE 2: JSE SRI Index Constituents

\begin{tabular}{lccccccccc}
\hline Headline & 2004 & 2005 & 2006 & 2007 & 2008 & 2009 & 2010 & 2011 & 2012 \\
\hline FTSE/JSE Top 40 Index & 31 & 32 & 34 & 34 & 36 & 34 & 36 & 36 & 36 \\
FTSE/JSE Mid Cap Index & 17 & 13 & 17 & 18 & 23 & 30 & 33 & 31 & 33 \\
FTSE/JSE Small Cap Index & 3 & 4 & 7 & 5 & 4 & 4 & 5 & 7 & 7 \\
Total & 51 & 49 & 58 & 57 & 61 & 67 & 74 & 74 & 76 \\
Companies Assessed & 74 & 58 & 62 & 72 & 105 & 109 & 106 & 109 & 108 \\
\hline
\end{tabular}

Source: JSE Limited (2013)

As indicated in TABLE 2, the JSE SRI Index is heavily influenced by the FTSE/JSE Top 40 Index companies, with a minimum of $78 \%$ of the companies between 2004 and 2012 making it into the JSE SRI Index. Since 2004, participation of mid-sized companies has increased, while the 
FTSE/JSE Small Cap Index provides the minimum contribution to the JSE SRI Index. Thus, the JSE SRI Index can be regarded as heavily weighted towards large to mid capitalised companies.

\section{LITERATURE REVIEW}

In this section, the literature on Socially Responsible Investing from International and South African studies is reviewed. In terms of International studies, the literature review is focused on studies that: (i) directly compare SRI fund performance to conventional investment fund performance and/or a benchmark, (ii) compare artificial/hypothetical SRI portfolios to a conventional benchmark, (iii) compare SRI index performance to conventional stock indices, and in terms of South African studies, the focus is on reviewing research that has been done in the SRI domain thus far.

\subsection{International studies}

The question of financial performance differences between socially responsible and conventional investments is a highly contentious issue in finance literature. From a Modern Portfolio Theory (MPT) perspective, SRI should under-perform fully diversified portfolios, since SRI-screened investments impose a 'constraint on the choice set of risk-return optimization' (Fu \& Shan, 2009:2). In other words, MPT posits that 'SRI investments are bound to suffer a financial loss of some magnitude due to inadequate diversification' (Barnett \& Salomon, 2006:1104).

A number of researchers, especially from developed countries, have sought to test this theoretical prediction of MPT. The central empirical question that these researchers have sought to answer is whether the constrained universe for an SRI investor significantly affects riskadjusted returns. Research in this field has predominantly followed three routes: (i) direct comparison of SRI fund performance to conventional investment fund performance and/or a benchmark, (ii) comparison of artificial/hypothetical SRI portfolios to a conventional benchmark, (iii) comparison of SRI index performance to conventional stock indices.

A dominant body of academic work (Hamilton, Jo \& Statman 1993; Statman, 2000; Bello, 2005; Kreander, Gray, Power \& Sinclair, 2005; Bauer, Koedijk \& Otten, 2005) compares the riskadjusted returns of SRI funds to conventional investment funds and/or a benchmark. Within this strand of literature, the dominant approach is the application of the matching approach (Statman, 2000; Bauer et al., 2005), a technique that focuses on comparing the financial performance of SRI and non-SRI funds with similar characteristics in terms of fund size and age and the investment universe (Schröder, 2004). As Schröder (2004) argued, the motivation of using such an approach is on aptly matching transaction costs and management fees of an SRI fund to those of a comparative non-SRI fund. However, as Chegut, Schenk and Scholtens (2011) argued, poor matching of SRI funds to conventional funds results in misspecification, which likely compromises empirical findings. In addition, Chegut et al. (2011) highlight the importance of properly defining what constitutes an SRI fund in the first place and also the need to account for survivorship bias.

In terms of comparing an SRI fund to a benchmark (e.g. Kreander et al., 2005), the majority of the empirical work employs simple regression of SRI funds' return against a market benchmark index. As can be expected, the choice of an appropriate benchmark in this type of research is problematic (Bauer et al., 2007). As Derwall et al. (2005:52) noted, in general SRI fund studies face the critique that they fail to incorporate 'non-quantifiable aspects such as management 
skill, unknown portfolio holdings and screening methods', rendering their results biased. Additionally, as Derwall et al. (2005: 52) argued, SRI fund studies 'cannot establish whether a social or environmental responsibility premium exists given that social and conventional fund holdings are not mutually exclusive'.

Despite the methodological differences and limitations, the dominant findings reported in fund studies indicate that there are no financial performance differences between SRI funds and conventional funds and/or benchmark indices (e.g. Kreander et al. 2005; Statman, 2000; Schröder, 2004, Scholtens, 2005; Bauer et al. 2007, Gregory \& Whittaker, 2007). According to Humphrey and Lee (2011), since funds are studied in groups, the dominant finding of nonstatistically significant performance differences might be due to the fact that fund studies do not account for the heterogeneous characteristics within funds caused by different SRI screens. As a consequence, some fund studies (e.g. Renneboog et al., 2008; Lee et al., 2010) investigate the influence of SRI fund differences on performance and risk (Humphrey \& Lee, 2011). In general, these studies show that instead of obtaining a negative or positive relationship between social and financial performance, a $\mathrm{U}$-shaped relation is found when differences in the intensity of social screens is considered (Barnett \& Salomon, 2006). According to Barnett and Salomon (2006:1106) the U-shaped relationship implies that: 'as the number of screens increases, performance first decreases and then increases'.

A second route (for e.g. Guerard, 1997; Hutton, D’Antonio \& Johnsen, 1998; Derwall et al., 2005) in SRI research follows the examining of statistical differences in the performance of artificial/hypothetical SRI portfolios to conventional benchmarks. The motive for using synthetic portfolios instead of actual SRI fund portfolios is the need to eliminate the influence of factors like fund investment policy and the fund manager's skill. As a result, synthetic portfolios are deemed to be affected only by general market conditions, hence facilitating a clearer distinguishing factor on the risk-return differences of SRI and conventional portfolios. An interesting study to note in this line of research is that of Derwall et al. (2005). Using two stock portfolios with different eco-efficiency, (defined by Derwall et al. (2005:52) as 'the economic value a company creates relative to the waste it generates'), Derwall et al. (2005) found that the stock portfolio with higher eco-efficiency yielded higher mean returns, while the lower portfolio yielded lower returns. Thus, they concluded that there was an eco-efficiency premium puzzle.

The third body of academic work in examining SRI performance, which is the focus of this study, focuses on financial performance comparison of SRI indices to the financial performance of conventional stock indices (Sauer, 1997; Kurtz \& DiBartolomeo, 1999; Statman, 2000, 2006; Garz, Volk \& Gilles, 2002; Schröder, 2007). Compared to SRI fund performance studies, this line of research is relatively new. According to Consolandi, Jaiswal-Dale, Poggiani and Vercelli (2009) the limited set of empirical studies focusing on the performance of SRI indices can be attributed to the fact that SRI indices have been introduced only recently, giving short data time series that render empirical findings unreliable. Nevertheless, this line of research has come to the fore with the advent of SRI indices globally (FTSE4Good, DJSI Indices, KLD 400 Social Index). Researchers in this line of study contend that researching performance of SRI through indices is more appealing than researching through SRI funds. For example, Statman (2006) argues that since transaction costs differ significantly across funds they influence return differences, thus blurring the effect of stock screening that the researcher wishes to study in the first place. In the vein, Schröder (2007) contends that the passive portfolio nature of indices makes it simpler to assess the influence of SRI screening on the risk-return profile, since indices are immune from 
the influence of transaction costs, market timing and the skill of the fund manager to produce outstanding performance.

Comparing returns of SRI indices to returns of conventional indices (benchmarks), the majority of empirical studies suggest the absence of statistically significant risk-adjusted return differences between SRI and conventional indices. Two early studies by Sauer (1997) and Statman (2000) in the US compared the financial performance of the DS 400 Index to the performance of S\&P 500 index in the 1990-1994 and 1990-1998 periods respectively. Using the single-factor CAPM Jensen's alpha and the Sharpe and Treynor ratios as measures of riskadjusted performance the two studies found no statistically significant risk-adjusted return differences between the DS 400 Index and the S\&P 500 index. In a later study, Statman (2006), employing data from the 1990-2004 period and using the Fama and French 3-factor model, found similar results to the 2000 study. Additionally, Statman (2006) reported that the Citizen Index, the Calvert Social index and the Dow Jones Sustainability index (US portion) performed similarly to the S\&P 500. Going beyond the US, Schröder (2007) considered 29 SRI indices that generally cover the global investment sphere. Employing single-and multi-equation regressions and spanning tests, Schröder (2007) reported that, regardless of the different SRI screening criterions among the indices, SRI stock indices showed indistinguishable risk-adjusted return differences to conventional indices. A noticeable finding from the study was that SRI indices exhibited higher risk levels relative to their comparative benchmarks. Similar to Schröder (2007), Managi, Tatsuyoshi and Akimi (2012) also report statistically non-significant performance differences between SRI indices in the US, UK and Japan and their respective benchmarks. Interestingly, Managi et al. (2012) considered two distinct market regimes (bull and bear) derived from a Markov switching model. Garz et al. (2002), unlike the index-employing studies cited in this section thus far, found that the European Dow Jones Sustainability Index in the 1999 to 2002 period marginally out-performed the DJ STOXX600 Index. Collison, Cobb, Power, and Stevenson (2008), similar to Garz et al. (2002), also reported out-performance. Specifically, Collison et al. (2008) found that FTSE4Good indexes out-performed their UK benchmarks in the 1996 to 2005 period, with performance differences being attributed to risk disparities.

\subsection{South African studies}

According to Viviers, Bosch, Smit and Buijs (2009) the first SRI funds were introduced in South Africa in 1992. In 2004, South Africa launched the first SRI index in an emerging economy. While SRI consciousness has grown steadily in the country, a limited number of studies in the SRI field exist. The majority of studies in the field delve into (i) the need to invest ethically (Viviers et al., 2009), (ii) opportunities and challenges in the SRI sector (Herringer et al., 2009; Heese, 2005) and (ii) the degree to which investors integrate ESG factors in their investment choices (Giamporcaro \& Pretorius 2012; Eccles et al., 2008).

The question of financial performance of SRI compared to conventional investing has been tackled in a limited way at the fund level. Viviers et al. (2008) reported that no empirical work on the performance of SRI funds existed in South Africa at the time of their study. Filling this gap, they compared the financial performance of SRI funds in the 1 June 1992 to 31 March 2006 period (with the whole sample period further divided into 3 sub-periods) to the financial performance of the FTSE/JSE All Share Index. Employing the Sharpe, Sortino and Upsidepotential ratios they reported (i) a curvilinear (U-shaped) relationship between SRI funds and their benchmarks i.e. SRI funds under-performed their respective benchmarks in the first two sub-periods (June 1992-August 1998; September 1998-March 2002), but significantly out- 
performed the benchmarks in the third sub-period (April 2002-March 2006) and (ii) SRI funds significantly under-performed the FTSE/JSE All Share Index in the second sub-period but had similar performance to the FTSE/JSE All Share Index in the first and third sub-periods. Viviers et al. (2008) concluded that the South African SRI sector might have gone through a 'learning effect' - i.e. asset managers increased their SRI market skills with the passage of time, resulting in better performance relative to time. In a recent study, Gladysek and Chipeta (2012) employed an event study methodology to investigate the influence of the news of firms' inclusion in the JSE SRI Index on firm value. Based on the market efficiency hypothesis, Gladysek and Chipeta (2012) hypothesised that firm value should be altered with the news of inclusion in the JSE SRI Index. Using the 2004-2009 period of analysis, Gladysek and Chipeta (2012) found insignificant average abnormal returns for firms in the JSE SRI Index for the years 2004, 2006, 2007, 2008 and 2009. Only in 2005 are positive significant abnormal returns found. In terms of postannouncement performance, Gladysek and Chipeta (2012) found that cumulative average abnormal returns were only positive in 2005 and 2007. As a result they conclude that the South African market disregards the news of inclusion in the JSE SRI Index as positive. In an extension of their study, they compared the performance of the JSE SRI Index to the FTSE/JSE All Share Index on a yearly basis from 2004 to 2009 and found no statistically significant financial performance differences between the JSE SRI Index and the FTSE/JSE All Share Index.

\section{DATA AND METHODOLOGY}

\subsection{Data}

This study compares the performance of the JSE SRI Index from its inception in May 2004 to August 2012 to the performance of four conventional market indices (FTSE/JSE All Share Index, FTSE/JSE Top 40 Index, FTSE/JSE Mid Cap Index and FTSE/JSE Small Cap Index). The FTSE/JSE All Share Index is a weighted index of all shares listed on the JSE Limited, the FTSE/JSE Top 40 Index is a tradable index made up of the 40 biggest companies as measured by market capitalisation from the FTSE/JSE All Share Index, the FTSE/JSE Mid Cap Index comprises of the next 61 largest companies (by market capitalisation) from the FTSE/JSE All Share Index that are not part of the FTSE/JSE Top 40 Index and the FTSE/JSE Small Cap Index is an index that tracks small companies that are not part of the FTSE/JSE TOP 40 and FTSE/JSE Mid Cap Indices. Historical closing monthly total return data (encompassing share price changes and dividend payments) of all the indices considered in this study were supplied by the JSE Limited. According to Ferson, Foerster and Keim (1993) monthly data has the advantage of limiting bid-ask and thin-trading influences. Data for the risk-free rate proxy (91-day TB rate) was sourced from the Reserve Bank of South Africa website (www.resevebank.co.za).

\subsection{Returns}

The first step in comparing the risk-adjusted return profile of the JSE SRI Index to the four selected conventional indices requires the calculation of index returns. Monthly returns for the each index in the full period and sub-periods were calculated as:

$$
R_{i t}=\frac{P_{i t}}{P_{i t-1}}-1
$$


where $R_{i t}$ is the return of index $i$ at time $t, P_{i t}$ is the value of index $i$ at time $t$ and $P_{i t-1}$ is the value of index $i$ at time $t-1$.

\subsection{Sharpe Ratio}

According to MPT, the return on an asset is influenced by risk. As such, the trade-off between return and risk must be considered. In this regard the ex post Sharpe Ratio (SR) was employed to compare the risk-return profile for the JSE SRI Index and the four conventional indices. The expost SR was calculated as follows:

$$
S R_{i t}=\frac{\mu_{i t}-R_{f t}}{\sigma_{i t}}
$$

where $S R_{i t}$ is the Sharpe Ratio for index $i$ in period $t, \mu_{i t}$ is the annualised mean monthly return for index $i$ in period $t, R_{f}$ is the risk-free rate (91-day Treasury Bill rate) and $\sigma_{i t}$ is the annualised standard deviation of the monthly returns of index $i$ in period $t$. In essence, equation (2) indicates the magnitude of excess return earned on index $i$ for each unit of volatility in a given period. Thus, the higher the $S R$ ratio is (due to an index having (i) smaller variance (ii) larger excess return and (iii) both (i) and (ii)), the better the performance of an index in a particular period. To this end, Sharpe ratio statistics of the JSE SRI Index in all the periods considered in this study are compared to those of the four conventional indices (FTSE/JSE All Share Index, FTSE/JSE Top 40 Index, FTSE/JSE Mid Cap Index and FTSE/JSE Small Cap Index).

\subsection{CAPM Regressions}

Similar to Sauer (1997), Statman (2000) and Schröder (2007), after calculating Sharpe ratios, statistical significance of performance differences of the JSE SRI Index and a market benchmark is empirically assessed through the use of a single-factor CAPM - i.e. monthly excess returns of the FTSE/JSE All Share Index (market benchmark) are regressed on the monthly excess returns of the JSE SRI Index as follows:

$$
S R I_{t}-R F_{t}=\alpha_{i}+\beta_{i}\left(J S E A L S I_{t}-R F_{t}\right)+\varepsilon_{t}
$$

where $S R I_{t}$ is the JSE SRI Index return in month $t, J S E A L S I_{t}$ is the FTSE/JSE All Share Index return in month $t, R F_{t}$, proxied by the 91-day TB rate, is the risk-free interest rate in period $t$, $\alpha_{i}$ is the Jensen's alpha, $\beta_{i}$ is the risk of JSE SRI Index in period t relative to the FTSE/JSE All Share Index and $\varepsilon_{t}$ is the is the disturbance term with $E\left(\varepsilon_{i t}\right)=0$ and $\operatorname{var}\left(\varepsilon_{i t}\right)=\sigma_{\varepsilon}{ }^{2}$.

Essentially, the alpha (also known as the Jensen alpha) in equation (3), if significant, indicates whether the JSE SRI Index out- or under-performed the benchmark index in a particular period i.e. out-performance is associated with a positive alpha coefficient and under-performance with a negative alpha coefficient. The beta $\left(\beta_{i}\right)$ coefficient indicates the volatility of the JSE SRI Index relative to the benchmark index: i.e. if $\beta_{i}>1$, then the risk of the JSE SRI Index would be higher than that of the FTSE/JSE All Share Index; if $\beta_{i}<1$, then the risk of the JSE SRI Index would be lower than that of the FTSE/JSE All Share Index; and if $\beta_{i}=1$, then the risk of the JSE SRI Index would be equal to that of the FTSE/JSE All Share Index.

As highlighted by Schröder (2007), additional factors like market timing and style of portfolio management are not included in equation (3) for the following reasons: (i) the JSE SRI Index is not frequently restructured; (ii) there is no active portfolio management, since indices 
represent a passive investment strategy; and (iii) the investment universe of the JSE SRI Index can be approximated by the selected benchmark. In effect, using the one-factor model (equation 3) eliminates two issues encountered in evaluating performance of investment funds: (i) market timing and (ii) availability of information on portfolio management style.

To ascertain whether investing in the JSE SRI Index is equivalent to investing in the benchmark index (FTSE/JSE All Share Index), the joint hypothesis: $H_{0}: \alpha_{1}=0$ and $\beta_{1}=1$ is tested using the Wald test. According to Schröder (2007), this constitutes a spanning test where the nonrejection of the null hypothesis indicates no differences in risk and return in the two indices i.e. a social investor suffers no penalty from investing in the JSE SRI Index. Estimates of alpha $\left(\alpha_{1}\right)$ and beta $\left(\beta_{1}\right)$ for the spanning hypothesis test are obtained from the results of running equation (3).

\section{EMPIRICAL RESULTS AND DISUSSION}

\subsection{Market conditions}

According to Huimin et al. (2010), the preference given to the single-period risk-return analysis approach in previous studies of SRI is inadequate, since SRI is likely to perform differently to non-SRI in different market conditions. Thus, following Natarajan (2011) graphical analysis is employed in this study to determine market conditions that prevailed during the study's sample period. FIGURE 2 shows the movements of all the indices under consideration in this study.

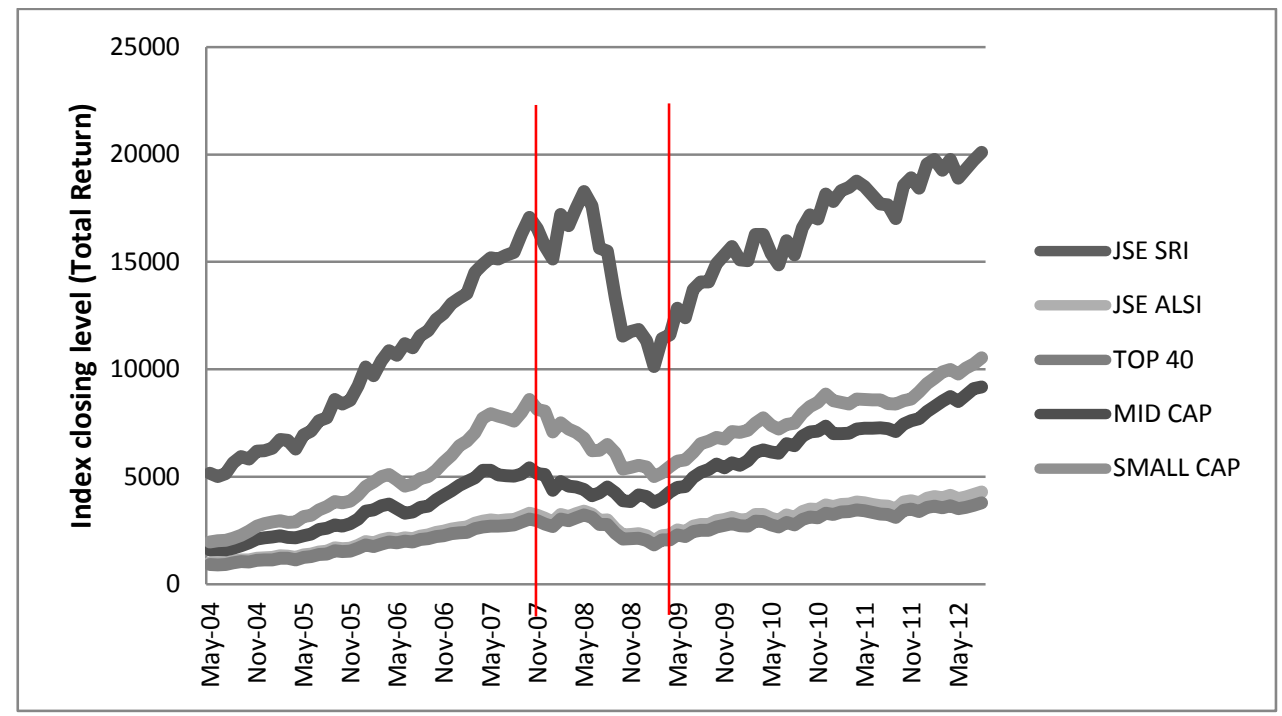

FIGURE 2: Indices movement: May 2004 - August 2012

Source: Author's analysis

If market conditions are to be factored in as discussed above the pertinent question is: Are conventional and SRI stock markets synchronised? FIGURE 2 shows that for all the indices in consideration, three market conditions prevailed during the May 2004 to August 2012 period. The period May 2004 - October 2007 is characterised by an upward trending of all the indices, the 
period November 2007 - February 2009 is characterised by a downward trending of all indices (coinciding with the financial global crisis) and the period March 2009 - August 2012 is characterised by another upward trending of all indices. As a result, the synchronisation of conventional stock and SRI markets is concluded, with three market phases prevailing: bull 1 (May 2004 - October 2007), bear (November 2007 - February 2009) and bull 2 (March 2009 - May 2011). Henceforth, the analysis in this study factored in the observed market phases.

\subsection{Risk-return Comparisons}

To allow risk-return comparisons of the JSE SRI Index and four conventional indices, we computed mean returns (equation 1), standard deviations, and risk-adjusted return ratios (equation 2). TABLE 4 presents risk-return comparison statistics for the full period and three sub-periods considered.

TABLE 4: Index performance: May 2004-August 2012

\begin{tabular}{|c|c|c|c|c|}
\hline Indices & $\begin{array}{c}\text { Annualised } \\
\text { Mean Return \% }\end{array}$ & $\begin{array}{c}\text { Annualised Std. } \\
\text { Dev. \% }\end{array}$ & $\begin{array}{c}\text { Annualised } \\
\text { Excess Return \% }\end{array}$ & Sharpe Ratio \\
\hline \multicolumn{5}{|c|}{ Full Period: May 2004 to August 2012} \\
\hline JSE SRI Index & 18.24 & 18.37 & 10.74 & 0.59 \\
\hline FTSE/JSE All Share Index & 19.21 & 17.17 & 11.72 & 0.68 \\
\hline FTSE/JSE TOP 40 Index & 18.77 & 18.21 & 11.27 & 0.62 \\
\hline FTSE/JSE Mid Cap Index & 22.59 & 15.57 & 15.10 & 0.97 \\
\hline $\begin{array}{l}\text { FTSE/JSE Small Cap } \\
\text { Index }\end{array}$ & 21.73 & 15.18 & 14.23 & 0.94 \\
\hline \multicolumn{5}{|c|}{ Bull period 1: May 2004 to 0ctober 2007} \\
\hline JSE SRI Index & 36.41 & 14.03 & 28.80 & 2.05 \\
\hline FTSE/JSE All Share Index & 36.34 & 13.12 & 28.73 & 2.19 \\
\hline FTSE/JSE TOP 40 Index & 36.10 & 13.84 & 28.50 & 2.06 \\
\hline FTSE/JSE Mid Cap Index & 37.25 & 14.03 & 29.64 & 2.11 \\
\hline $\begin{array}{l}\text { FTSE/JSE Small Cap } \\
\text { Index }\end{array}$ & 44.93 & 13.32 & 37.32 & 2.80 \\
\hline \multicolumn{5}{|c|}{ Bear period : November 2007 to February 2009} \\
\hline JSE SRI Index & -35.43 & 25.32 & -46.05 & $-0.12^{\star}$ \\
\hline FTSE/JSE All Share Index & -33.61 & 22.92 & -44.23 & $-0.10 \star$ \\
\hline FTSE/JSE TOP 40 Index & -34.61 & 24.32 & -45.24 & $-0.11^{\star}$ \\
\hline FTSE/JSE Mid Cap Index & -23.60 & 22.14 & -34.23 & $-0.08 *$ \\
\hline $\begin{array}{l}\text { FTSE/JSE Small Cap } \\
\text { Index }\end{array}$ & -38.11 & 18.78 & -48.73 & $-0.09 \star$ \\
\hline
\end{tabular}




\begin{tabular}{lcccc}
\hline \multicolumn{1}{c}{ Indices } & $\begin{array}{c}\text { Annualised } \\
\text { Mean Return \% }\end{array}$ & $\begin{array}{c}\text { Annualised Std. } \\
\text { Dev. \% }\end{array}$ & $\begin{array}{c}\text { Annualised } \\
\text { Excess Return \% }\end{array}$ & Sharpe Ratio \\
Bull period 2: March 2009 to August 2012 & 20.96 & 16.07 & 14.76 & 0.92 \\
JSE SRI Index & 22.61 & 15.12 & 16.41 & 1.09 \\
FTSE/JSE All Share Index & 22.19 & 16.47 & 15.99 & 0.97 \\
FTSE/JSE TOP 40 Index & 25.89 & 10.94 & 19.69 & 1.80 \\
FTSE/JSE Mid Cap Index & 21.88 & 9.36 & 15.68 & 1.68 \\
$\begin{array}{l}\text { FTSE/JSE Small Cap } \\
\text { Index }\end{array}$ & & &
\end{tabular}

Source: Author's analysis

Note: Annualised mean = mean monthly return multiplied by 12. Annualised standard deviation $=$ monthly standard deviation multiplied by the square root of 12 . *Israelsen (2005) modified Sharpe ratio

As shown in TABLE 4, in the full sample period (May 2004 to August 2012) the JSE SRI Index has the lowest mean annual return (18.24\%). The FTSE/JSE Mid Cap Index has the highest mean annual return of $22.59 \%$. Thus, for the full sample period, conventional indices deliver higher returns. To establish the risk-return relationship (is a high return due to high risk and vice versa?) for the indices, risk-adjusted returns were compared (Schröder, 2007). In terms of risk, the JSE SRI Index has the highest volatility of $18.37 \%$ (an excess standard deviation of $1.2 \%$ relative to the market portfolio). Thus, compared to conventional indices, the JSE SRI Index exhibits a poorer risk-return trade-off in the full sample period (relative to the market benchmark, the Mid Cap and Small Cap indices have at least $1.2 \%$ less risk). Another more restricted basket of stocks, the FTSE/JSE Top 40 Index, which is highly correlated to the JSE SRI Index (because of the high number of index constituents shared with the JSE SRI Index), also exhibits the same poor risk-return trade-off. According to MPT, a restricted investment universe results in an inefficient portfolio with lower risk-adjusted returns (Lee et al., 2010). Given the mean return and standard deviation results, the Mid Cap has the highest risk-adjusted performance measure (Sharpe Ratio) of 0.97 , and the JSE SRI Index has the lowest Sharpe Ratio of 0.59. In sum, the Mid Cap out-performs all the indices and the JSE SRI Index under-performs all the four conventional indices. These results suggest that there might be a risk-adjusted return penalty for investing in the JSE SRI Index and that the index exhibits a higher risk level, thus confirming MPT principles.

To establish if the results obtained for the full sample period prevailed across different time periods (accounting for changes in market conditions), the risk-return relationship was analysed for three sub-periods: bull 1 (May 2004 - October 2007), bear (November 2007 February 2009) and bull 2 (March 2009 - August 2012). TABLE 4 shows that the two bull periods were characterised by low volatility and positive returns, while the bear period, which coincided with the global financial crisis, was characterised by high volatility and negative returns. In the bear market, the JSE SRI Index has the highest volatility (25.32\%) compared to all conventional indices and in the bull periods, the JSE SRI Index is only marginally less volatile than one index in each period: the Mid Cap in bull 1 period and the Top 40 in bull 2 period. In terms of risk-adjusted performance, the Sharpe ratios show that the JSE SRI Index under-performs all the conventional indices in bull period 1 , and in bull period 2 the JSE SRI Index out-performs only the FTSE/JSE Mid Cap Index. In the bear period, the traditional Sharpe ratios calculated were negative. As 
Israelsen (2005) and Macleod and Vuuren (2004) show, performance ranking in bear periods using the traditional Sharpe ratios leads to erroneous rankings, since the notion that the Sharpe ratio decreases as the measure of risk (standard deviation) increases is not satisfied i.e. in bear periods characterised by negative excess returns, the inverse of having the Sharpe ratio decreasing as risk increases occurs. To solve this anomaly, Israelsen (2005) suggested the introduction of an exponent to the denominator (excess return divided by absolute excess return), which in effect results in the multiplication of the traditional Sharpe ratio numerator with standard deviation (denominator from the traditional Sharpe ratio). Thus, in order to achieve meaningful ranking of the indices in the bear period, as indicated in TABLE 4, the Israelsen (2005) modification was used.

Similar to the bull period 1 ranking results, the modified Sharpe ratio shows that the JSE SRI Index under-performs all the indices in this sub-period. The highest ranking index in the bear period is the FTSE/JSE Mid Cap Index, followed by the FTSE/JSE Small Cap Index. Thus, the normally assumed idea that SR stocks may provide hedging benefits in bear conditions cannot be supported. In general, the results presented in TABLE 4 imply that there was a cost in terms of risk-adjusted returns involved in investing in the JSE SRI Index in both bull and bear market conditions.

\subsection{Index performance and spanning tests}

The single-factor CAPM (equation 3) is employed to test whether the performance differences of the SRI and conventional stocks reported in the previous section are actually statistically significant. As discussed in section 4.4, from the CAPM model the performance of the JSE SRI Index is compared to the FTSE/JSE All Share Index (proxy for the market benchmark) in terms of the Jensen's alpha and the beta coefficient. Additionally, to establish if an investment in the JSE SRI Index is equivalent to investing in the FTSE/JSE All Share Index in terms of risk and return, a test of the joint hypothesis $H_{0}: \alpha_{t}=0 \& \beta_{t}=0$ (Spanning test) was carried out.

TABLE 5 shows the results of the performance statistics and spanning tests for the full sample period and three sub-periods.

As shown in TABLE 5 , the market benchmark in all market conditions explains more than $97.5 \%$ of the variation in the JSE SRI Index, justifying the implementation a single-factor CAPM. In terms of index performance comparison, all the estimates of the Jensen alpha coefficient (except in the bear period) are negative. For the full period (May 2004-August 2012) and bull period 2 (March 2009 - August 2012), the Jensen alphas are statistically distinguishable from zero, implying that the JSE SRI Index under-performs the conventional index. These results are similar to the under-performance of SRI that what was reported with the Sharpe Ratio statistic. In all market conditions considered, estimates of the beta coefficient are significant and greater than one, indicating that the JSE SRI Index's risk relative to the FTSE/JSE All Share Index is greater (beta ranges from 1.056 to 1.096). Similar to the findings of DiBartolomeo and Kurtz (1999) and Schröder (2007), these results confirm the MPT notion that regards SRI investment as being riskier than an unconstrained investment universe.

In terms of ascertaining if the JSE SRI Index's returns can be replicated by the conventional benchmark, the hypothesis for spanning is rejected in three of the four periods. Specifically, spanning tests revealed that only in bull period l (May 2004-February 2009) is the JSE SRI Index spanned by the benchmark. The plausible reason for the rejection of spanning in the other periods is the difference in relative risk. 
TABLE 5: Index performance and spanning tests

$\begin{array}{ccccc}\text { Index } & \text { Adjusted } & \text { Alpha } & \text { Beta } & \text { Spanning Test } \\ & R^{2} & H_{0}: \alpha=0 & H_{0}: \beta=0 & H_{0}: \alpha_{t}=0 \text { and } \beta_{t}=1\end{array}$

Full period: May 2004 to August 2012

JSE SRI Index $98.56 \quad-0.001(-2.41) \quad 1.060(81.86) \quad 11.93(0.0000)$ *

Bull period 1: May 2004 to October 2007

JSE SRI Index $97.50 \quad-0.001(-1.08) \quad 1.056(39.56) \quad 2.20(0.1248)$

Bear period : November 2007 to February 2009

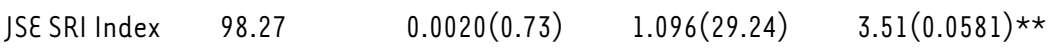

Bull period 2: March 2009 to August 2012

JSE SRI Index $98.94 \quad-0.002(-2.82) \quad 1.058(61.81) \quad 7.44(0.0018)$ *

Source: Author's analysis

Notes: The Beta and Alpha columns show the value of the test statistics with t-stats enclosed in brackets, the spanning test column shows the test statistic with $p$-values enclosed in brackets.

$(\star),(\star \star)$ Significant at $1 \%$ and $10 \%$ level respectively

Thus, in terms of risk-return, the inference that can be drawn from the spanning tests is that there is a statistically significant difference between the JSE SRI Index and the FTSE/JSE All Share Index in the full period (May 2004 - August 2012), bear period (November 2007 - February 2009) and bull period 2 (March 2009 - August 2012). The implication of these results is that an investor who had an exclusive holding of SR stocks realised lower risk-adjusted returns relative to the broader market benchmark in the aforementioned periods.

\subsection{Performance, Risk and Spanning-Tests: Synthetic Indices}

Since the JSE SRI Index is a subset of the FTSE/JSE All Share Index, by implication there is an inherent overlap of stocks between the conventional index (FTSE/JSE All Share Index) and the JSE SRI Index. In other words, the same socially responsible stocks in the JSE SRI Index are also contained in the benchmark used in the CAPM regression analysis. Resultantly, the analysis done in section 5.3 possibly distorts risk-return differences between conventional and SR stocks. With the two indices sharing a significant number of shares, the spanning tests conducted in section 3 were supposed to be biased in the direction of non-rejection of the spanning test. However, this assumption is not necessarily true in this study, since three of the four tests were rejected. Some previous studies (e.g. Schröder, 2007) did not endeavour to disentangle the benchmark into SR and non-SR stocks before conducting the CAPM regressions and Statman (2006) cited unavailability of data to facilitate disentanglement. Sensing this to be a potential critique and also driven by the need to truly ascertain performance, risk and return differences between conventional stocks and the JSE SRI Index stocks, it was worthwhile creating a synthetic index that would represent purely conventional stocks and compare it with a pure SR index. This was achieved by creating an index that constitutes only those stocks from the FTSE/JSE All Share Index that failed to satisfy the JSE SRI Index inclusion criterion in any month of the study period. The created index was titled the Synthetic Conventional index ( $\mathrm{SCl}$ ). To ensure the validity of the synthetic index and to eliminate the possibility of differences in risk-return comparisons 
emanating from differences in index construction methodologies (this would be highly likely if the constructed conventional index ( $\mathrm{SCl}$ ) is compared to the official JSE SRI Index), a second synthetic index was created, titled the JSE SRI Synthetic Index. This index was fundamentally a rework of the official JSE SRI Index and used for methodology verification (compared to the official JSE SRI Index). The SCI and JSE SRI Index Synthetic indices were computed through the use of the modified Laspeyres method, the same methodology applied by FTSE/JSE in computing the official FTSE/JSE indices. Declared dividends were also considered to arrive at Total Return Indices (TRI) for the May 2004 to August 2012 period.

FIGURE 3 shows the time series movement of the official JSE SRI Index and the constructed JSE SRI Synthetic Index.

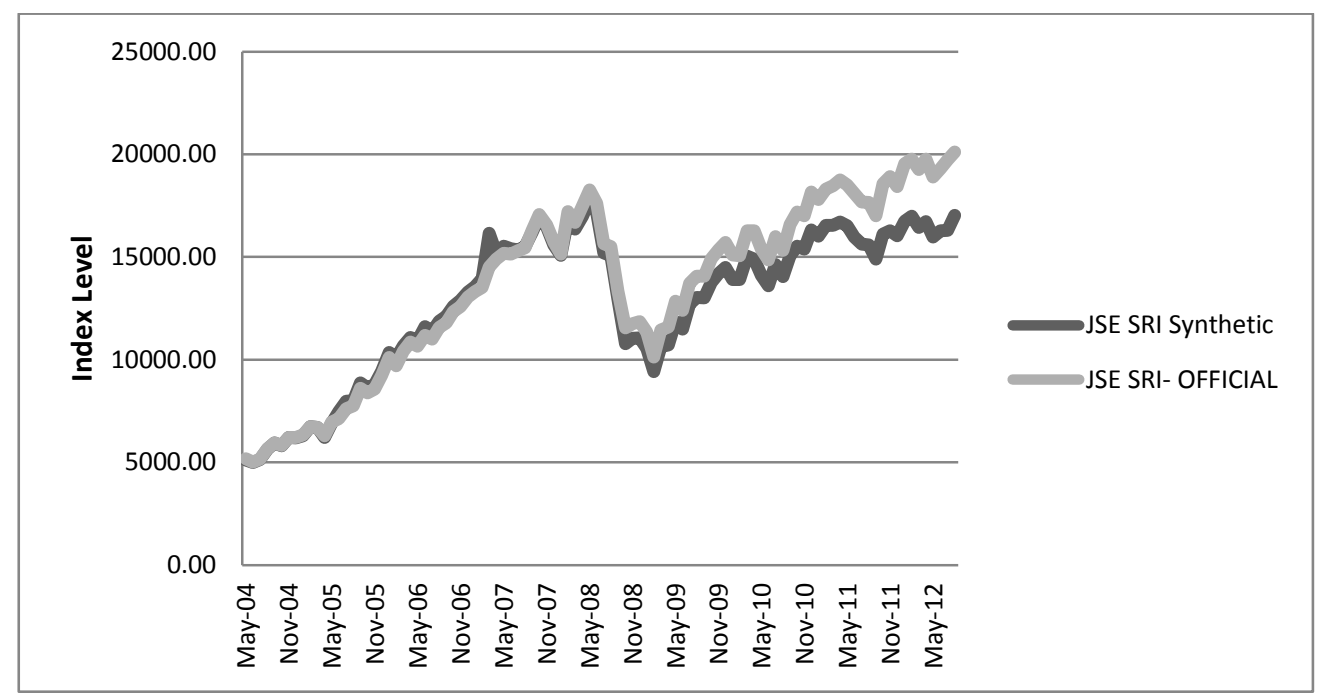

\section{FIGURE 3: JSE SRI vs. JSE SRI SYNTHETIC}

\section{Source: Author's analysis}

The correlation coefficient between the JSE SRI Index and the computed JSE SRI (SCI) for the periods considered in this study are as follows: full period (May 04 - August 12) - 0.980, bull 1 (May 04 - 0ct 07) - 0.997, bear (Nov 07 - Feb 09) - 0.998 and bull 2 (March 09 - Aug 2012) 0.984 . The correlation coefficient statistics confirmed the validity of the methodology employed in the construction of the synthetic indices. As a result, the $\mathrm{SCI}$ representing purely non-SRI stocks could be compared to the JSE SRI Index representing socially responsible stocks.

As was done in section 5.3 with the FTSE/JSE All Share Index as the market benchmark, the performance differences between the JSE SRI Index and the $\mathrm{SCl}$ are tested for statistical significance through the use of the single-factor CAPM. From the CAPM regression, the alpha coefficient indicates whether the JSE SRI Index under (-) or out (+) performs the benchmark $(\mathrm{SCl})$, while the beta coefficient shows the relative risk of the JSE SRI Index to the SCI. TABLE 6 presents the estimates of alpha and beta and also spanning test statistics obtained with the $\mathrm{SCl}$ as the benchmark. 
TABLE 6: Index performance and spanning tests: JSE SRI Index vs. SCI

\begin{tabular}{|c|c|c|c|c|}
\hline Index & Adjusted $R^{2}$ & $\begin{array}{c}\text { Alpha } \\
H_{0}: \alpha=0\end{array}$ & $\begin{array}{c}\text { Beta } \\
H_{0}: \beta=0\end{array}$ & $\begin{array}{c}\text { Spanning Test } \\
H_{0}: \alpha_{t}=0 \text { and } \beta_{t}=1\end{array}$ \\
\hline
\end{tabular}

Full period: May 2004 to August 2012

JSE SRI Index $\quad 58.05 \quad-0.0008(-0.21) \quad 0.85(11.69) \quad 2.267(0.109)$

Bull period 1: May 2004 to October 2007

JSE SRI Index $\quad 47.20 \quad 0.0071(1.33) \quad 0.76(6.06) \quad 1.638(0.207)$

Bear period : November 2007 to February 2009

JSE SRI Index $\quad 37.44 \quad-0.0095(-0.55) \quad 0.74(3.15) \quad 0.619(0.553)$

Bull period 2: March 2009 to August 2012

JSE SRI Index $64.28 \quad-0.0074(-1.54) \quad 0.98(8.65) \quad 2.810(0.072)$ *

Source: Author's analysis

Notes: The Beta and Alpha columns show the value of the test statistics with t-stats enclosed in brackets, while the spanning test column shows the test statistic with $p$-values enclosed in brackets.

(*) Significant at $10 \%$ level

Similar to what was reported in section 5.3, the JSE SRI Index has three out of four negative Jensen alphas in the periods considered. However, all the alphas are statistically indistinguishable from zero. This means that unlike the results of section 5.3, which indicated that the JSE SRI Index had statistically significant under-performance in the full period and bull period 2, the JSE SRI Index suffers no statistically significant under-performance in all the periods considered. Thus, the risk-adjusted return achieved by the JSE SRI Index is not statistically different from the SCI, implying that the underlying stocks in the JSE SRI Index seem statistically to perform as well as (or as badly as) conventional stocks. This finding is in line with Sauer (1997), DiBartolomeo and Kurtz (1999), Statman (2006) and Schröder (2007), among others. The beta statistic shows that in all the periods the JSE SRI Index has lower $(\beta<1)$ risk than the conventional benchmark. The adjusted $\mathrm{R}^{2}$ reported are much lower than those reported in section 5.3, showing that a single-factor CAPM model with the $\mathrm{SCl}$ as a benchmark is not an adequate model to explain the risk-return relationship. The spanning tests are not rejected for the full period, bull period 1 and the bear period, but for bull period 2, spanning is rejected only at the $10 \%$ level of significance. Since spanning is generally accepted, it can be concluded that when the benchmark is composed of purely conventional stocks, the JSE SRI Index can be directly replicated by the benchmark.

Altogether, the findings presented in this section refute the portfolio theory, which postulates that conventional stocks should out-perform SR stocks in terms of risk-adjusted returns. These findings are in line with results from previous research (Statman, 2000, 2006; Sauer, 1997; DiBartolomeo and Kurtz, 1999; Garz et al., 2002; Statman, 2006; Schröder, 2007), which reports that an investment in SR stocks does not result in lower risk-adjusted returns. Perhaps what is important to ask is: Why do the results presented in this section diverge from the results presented in the previous section? A plausible reason is that filtering out SR stocks from the market benchmark (FTSE/JSE All Share Index) and creating the Synthetic Conventional Index 
(SCI) render the market benchmark a restricted basket of stocks similar to the restricted JSE SRI Index basket.

\section{CONCLUSION}

According to MPT, the restricted investment universe of SRI limits the potential for portfolio diversification. As a result, SRI portfolios are expected to under-perform conventional portfolios. However, supporters of SRI contend that any loss in deriving mean-variance efficient portfolios as a result of a constrained investment universe is compensated for by the desirable profile characteristics of the screened assets. This view is anchored in the belief that portfolio screens eliminate firms with undesirable characteristics that the market or society will eventually penalise over time (e.g. with higher capital costs and stricter regulation) (Renneboog et al., 2008).

Since the prominence of SRI is continually growing in South Africa, this study sought to determine empirically whether there are any significant differences in terms of risk-adjusted returns between investing in SR and conventional stocks in the South African financial market. Unlike the majority of previous studies, which compare the financial performance of SRI funds to the performance of conventional funds, this study followed research that circumvents the combined hypothesis problem (testing both fund-management skill and underlying asset performance (Schröder, 2004)) by employing stock market indices. From the universe of conventional indices, the JSE SRI Index was compared to the FTSE/JSE All Share Index, FTSE/JSE Top 40 Index, FTSE/JSE Mid Cap Index and FTSE/JSE Small Cap Index for the May 2004 to August 2012 period. Using graphical analysis the study period was divided into three sub-periods (bull 1 (May 2004 - October 2007), bear (November 2007 - February 2009) and bull 2 (March 2009 - May 2011) to control for the likely influence of market conditions.

Using the Sharpe ratio as a performance measure, the JSE SRI Index was first compared to a set of selected conventional indices. The results of the analysis generally indicate that the JSE SRI Index exhibits a poorer risk-return trade-off than the conventional indices. Another more restricted basket of stocks, the FTSE/JSE Top 40 Index, which is highly correlated to the JSE SRI (because of the high number of index constituents shared with JSE SRI Index), also exhibits the same poor risk-return trade-off. The FTSE/JSE Mid Cap and FTSE/JSE Small Cap indices are the two best-performing indices in all the periods considered.

As is prevalent in studies of this nature, the JSE SRI Index's performance was subsequently compared to the market benchmark, the FTSE/JSE All Share Index, using the single-factor CAPM. Consistent with the results obtained from the Sharpe ratio ranking, the Jensen alpha estimates from the CAPM model show that the JSE SRI Index under-performs the FTSE/JSE All Share Index in all periods except in the bear period. For the full period (May 2004-August 2012) and bull period 2 (March 2009 - August 2012), the Jensen alphas are statistically distinguishable from zero, implying that the JSE SRI Index under-performed to a statistically significant degree in these periods. In addition, the JSE SRI INDEX exhibits higher relative risk to the benchmark in all the periods under consideration. The hypothesis for spanning is rejected in three of the four periods considered largely due to the JSE SRI Index's relatively higher risk compared to the benchmark. This implies that there are indeed risk-return differences between the JSE SRI and the FTSE/JSE All Share Index - hence investing in the two indices yields different risk-adjusted returns. 
To credibly distinguish the performance of SR stocks from conventional stocks, a synthetic index $(\mathrm{SCl})$ representing purely conventional stocks was constructed and employed as the benchmark in additional CAPM regressions. The resultant CAPM regressions indicated that the JSE SRI Index still has three out of four negative Jensen alphas in the periods considered. However, all the alphas are statistically indistinguishable from zero. This differs from the CAPM result with the FTSE/JSE All Share Index as a benchmark, which has two statistically significant underperformances. Further, the spanning tests are not rejected for the full period, bull period 1 and the bear period; only in bull period 2 is spanning rejected, albeit at the $10 \%$ level of significance. Thus, it can be concluded that the risk-return performance levels of the JSE SRI Index and the SCI are similar.

In general, the results of this study indicate that the JSE SRI Index under-performs both the FTSE/JSE All Share Index and the Synthetic Conventional index, as indicated by six out of eight negative Jensen alphas, even though only two are statistically significant. As a result, socially conscious investors might not be able to replicate the risk-adjusted returns of South African conventional stock. However, the results obtained in this study when the JSE SRI Index is compared to an index that represents purely conventional stocks also show that there is no statistically significant difference between SR stocks and pure conventional stocks. Hence, it can be speculated that the constrained portfolio hypothesis is believed to explain why the JSE SRI Index is likely to perform as well as the Synthetic Conventional index. By filtering out SR stocks from the FTSE/JSE All Share Index and creating the SCI, by implication the JSE SRI Index, which is a restricted portfolio, is effectively being compared to another restricted portfolio. As a result no difference in risk-adjusted returns should be expected. Since the non-socially conscious investor has a full investment universe, in line with MPT, the conclusion from this paper is that SRI came at a cost in South Africa in the period considered.

One interesting aspect of the study's results is the performance of mid-and small-cap companies. Investors on the JSE Limited are biased towards investing in large caps because of thin-trading and high risk concerns in mid-and small-cap stocks. However, the results of this study indicate that mid-and small-cap stocks out-performed the Top 40 stock with relatively lower risk levels. As a result, there are risk-return benefits for investors who consider mid-and small-cap stocks. As for the JSE SRI Index composition, the challenge is to assimilate the midand small-cap companies into the index.

\section{LIST OF REFERENCES}

Barnett, M.L. \& Salomon, R.M. (2006). Beyond dichotomy: The curvilinear relationship between social responsibility and financial performance, Strategic Management Journal, 27(11), pp.1101-1122.

Bauer R, Derwall J, Otten R. (2007). The ethical mutual fund performance debate: New evidence from Canada. Journal of Business Ethics, 70, pp. 111-124.

Bauer, R., Koedijk, K. \& Otten, R. (2005). International evidence on ethical mutual fund performance and investment style, Journal of Banking \& Finance, 29(7), pp.1751-1767.

Bello, Z.y. (2005). Socially responsible investing and portfolio diversification, The Journal of Financial Research, 28(1), pp. 41-57.

Chegut, A., Schenk, H. \& Scholtens, B. (2011). Assessing SRI fund performance research: Best practices in empirical analysis. Sustainable Development, 19, pp. 77-94. 
Collison, D.J., Cobb, G., Power, D.M. \& Stevenson, L.A. (2008). The financial performance of the FTSE4Good indices, Corporate Social Responsibility and Environmental Management, 15(1), pp. 1428.

Consolandi, C., Jaiswal-Dale, A., Poggiani, \&. \& Vercelli, A. (2009). Global standards and ethical stock indexes: The case of the Dow Jones Sustainability Stoxx index, Journal of Business Ethics, 87, pp.185197.

Israelsen, C. (2005). A refinement to the Sharpe ratio and information ratio, Journal of Asset Management, 5(6), pp. 423-427.

Derwall, J., Guenster, N., Bauer, R. \& Koedijk, K. (2005). The eco-efficiency premium Puzzle, Financial Analysts Journal, 61(2), pp. 51-63.

DiBartolomeo D, Kurtz L. 1999. Managing Risk Exposures of Socially Screened Portfolios. Northfield Information Services: Boston, MA. [Online] Available: http://www.northinfo.com/documents/63.pdf. (Accessed 10 September 2012).

Eccles N.S., Nicholls, S. \& De Jongh, D. (2008). The state of responsible investment in South Africa. Pretoria: UNISA Centre for Corporate Citizenship. [Online] Available:

http://www.unepfi.org/fileadmin/documents/The_State_of_Responsible_Investment_01.pdf. (Accessed 26 August 2012).

Ferson, W., Foerster, S. \& Keim, D. (1993). General tests of latent variable models and mean-variance spanning, Journal of Finance, 48(1), pp. 131-156.

Fu, S. \& Shan, L. Corporate equality and equity prices: Doing well while doing good? Economics and Econometrics Research Institute Research Paper Series No 09/2009. [Online] Available: http://www.eeri.eu/documents/wp/EERI_RP_2009_09.pdf. (Accessed 15 September 2012).

Galema, R., Plantinga, A. \& Scholtens, B. (2008). The stocks at stake: Return and risk in socially responsible investment, Journal of Banking \& Finance, 32(12), pp. 2646-2654.

Garz, H., Volk, C. \& Gilles, M. (2002). More gain than pain. SRI: Sustainability pays off. WestLB Panmure. [Online] Available:

http://s3.amazonaws.com/zanran_storage/www.djindexes.com/ContentPages/10244444.pdf. (Accessed 14 April 2012).

Giamporcaro, S. \& Pretorius, L. (2012). Sustainable and responsible investment (SRI) in South Africa: A limited adoption of environmental criteria, Investment Analysts Journal, 75, pp. 1-19.

Gladysek, 0. \& Chipeta, C. (2012). The impact of Socially Responsible Investment Index constituent announcements on firm price: Evidence from the JSE, South African Journal of Economic \& Management Sciences, 15(4), pp. 429-439.

Global Sustainable Investment Alliance (GSIA). (2012). Global Sustainable Investment Review.

Greening, D.W. \& Turban, D.B. (1997). Corporate social performance and organizational attractiveness to prospective employees, Academy of Management Journal, 40, pp. 658-672.

Gregory, A. \& Whittaker, J. (2007). Performance and performance persistence of 'ethical' unit trusts in the UK, Journal of Business Finance \& Accounting, 34(7-8), pp. 1327-1344.

Guerard J.B. (1997). Is there a cost to being socially responsible in investing? The Journal of Investing, 6(2), pp.11-18.

Hamilton, S., Jo, H. \& Statman, M. (1993). Doing well while doing good? The investment performance of socially responsible mutual funds, Financial Analysts Journal, 49(6), pp.62-66. 
Heese, K. (2005). The development of socially responsible investment in South Africa: experience and evolution of SRI in global markets, Development Southern Africa, 22(5), pp. 729-739.

Herringer, A., Firer, C. \& Viviers, S. (2009). Key challenges facing the socially responsible investment (SRI) sector in South Africa, Investment Analysts Journal, 70, pp. 11-26.

Hong, H. \& Kostovetsky, L. (2012). Red and blue investing: Values and finance. Journal of Financial Economics, 103, pp. 1-19.

Huimin, L., Kong, C.A.W., Eduardo, R. (2010). Socially Responsible Investment in good and bad times, International Research Journal of Finance \& Economics, 54, pp. 1502-165.

Humphrey, J.E. \& Lee, D.D. (2011). Australian Socially Responsible Funds: Performance, Risk and Screening intensity, Journal of Business Ethics, 102(4), pp. 519-533.

Israelsen, C.L. (2005). A refinement to the Sharpe ratio and Information ratio, Journal of Asset Management, 5(6), pp. 423-427.

Hutton, R.B., D’Antonio, L. \& Johnsen, T. (1998). Socially responsible investing, Business and Society Magazine, 37(3), pp. 281-306.

Johannesburg Stock Exchange (2011). Background and Selection Criteria 2011. Johannesburg.

[Online] Available:

http://www.jse.co.za/Libraries/SRI_Criteria_Documents/01_Background_and_Criteria_2011.sflb.as hx. (Accessed 25 August 2012).

Johannesburg Stock Exchange (2013). Information briefing: Annual index review. Johannesburg.

[Online] Available: http://www.jse.co.za/Libraries/SRI-2013-

Presentations/2013_SRI_index_company_briefing_presentation.sflb.ashx. (Accessed 12 December 2013).

Kempf, A. \& Osthoff, P. (2007). The effect of socially responsible investing on portfolio performance, European Financial Management, 13(5), pp.908-922.

Knoll, M.S. (2002). Ethical screening in modern financial markets: The conflicting claims underlying socially responsible investment, The Business Lawyer, 57(2), pp. 681-726.

Kreander N., Gray R., Power, D. \& Sinclair, C. (2005). Evaluating the performance of ethical and nonethical funds: A matched pair analysis. Journal of Business Finance and Accounting, 32(7-8), pp. 1465-1493.

Lee, D.D., Humphrey, J.E., Benson, K.L. \& Ahn, J.Y.K. (2010). Socially responsible investment fund performance: the impact of screening intensity, Accounting \& Finance, 50(2), pp.351-370.

Managi, S., Tatsuyoshi, 0. \& Akimi, M. (2012). Do Socially Responsible Investment

Indexes outperform conventional indexes? MPRA Paper No. 36662. [Online] Available: http://mpra.ub.uni-muenchen.de/36662/. (Accessed 13 August 2012).

McLeod, W. \& Vuuren, V.G. (2004). Interpreting the Sharpe ratio when excess returns are negative, Investment Analysis Journal, 59, pp.15-20.

Natarajan, M.D. (2011). Equanimity of risk and return relationship between Shariah Index and General Index in India, Journal of Economics \& Behavioural Studies, 2(5), pp. 213-222.

Renneboog, L., Horst, J.T. \& Zhang, C. (2008). The price of ethics and stakeholder governance: The performance of socially responsible mutual funds, Journal of Corporate Finance, 14(3), pp.302-322. 
Sauer, D. (1997). The impact of social-Responsibility screens on investment performance: Evidence from the Domini 400 Social Index and Domini Equity Mutual Fund, Review of Financial Economics, 6(2), pp.137-149.

Scholtens, B. (2005). Style and performance of Dutch socially responsible investment funds, The Journal of Investing, 14(1), pp. 63-72.

Schröder, M. (2004). The performance of socially responsible investments: Investment funds and indices, Financial Markets and Portfolio Management, 18(2), pp.122-142.

Schröder, M. (2007). Is there a difference? The performance characteristics of SRI equity indices, Journal of Business Finance \& Accounting, 34(1\&2), pp. 331-348.

Statman, M. (2000). Socially responsible mutual funds, Financial Analysts Journal, 56(3), pp.30-39.

Statman, M. (2006). Socially responsible indexes. The Journal of Portfolio Management, 32(3), pp.100-109.

Viviers, S., Bosch, J.K., Smit, Evd M. \& Buijs, A. (2008). The risk-adjusted performance of responsible investment funds in South Africa, Investments Analysts Journal, 68 (November), pp. 1-17.

Viviers, S., Bosch, J.K., Smit, \& vd M. \& Buijs, A. (2009). Responsible investing in South Africa, Investment Analysts Journal, 69, pp. 3-16.

Waddock, S. \& Graves, S. (1997). The corporate social performance-financial performance link, Strategic Management Journal, 18, pp. 303-319. 
Chawana 